\title{
Biomass from Palm Oil Waste as a Renewable Energy Source with Community Benefits
}

\author{
Schafir Thomas ${ }^{1}$, Csery Andres ${ }^{1}$ \\ Eötvös Loránd University, Hungaria
}

\begin{abstract}
This article addresses Biomass as a green energy source. The oil palm by-product is commonly accepted as a suitable raw material for power plant diesel. Numerous countries are beginning to transition to palm biomass as a fuel source due to its environmental friendliness and green nature. Renewable energy management needs technology, since it would only be produced to generate energy from natural products that will never run out. Nevertheless, the life of the oil palm plantation itself is very poor. For example, the influence of oil palm plantations on natural capital in green land has decreased or even vanished. Indeed, the biological organisms that inhabit it are the primary source of life for the population, especially the indigenous people who live in close proximity to the soil.
\end{abstract}

Keywords: Palm Oil, Biomass, Renewable Energy

Received : March 1, 2021

Received in Revised: March 25, 2021

Accepted: April 7, 2021

\section{Introduction}

Oil palm plantations and crude palm oil refining often result in the production of biomass, which is often referred to as palm oil industry waste. When this biomass is discarded or left alone, it often becomes a concern. Indeed, oil palm biomass can be used for a variety of uses, including conversion into environmentally sustainable fuels, such as those used to generate electricity.

The oil palm by-product is commonly accepted as a suitable raw material for power plant diesel. Numerous countries are beginning to transition to palm biomass as a fuel source due to its environmental friendliness and green nature (Kelly-Yong et al., 2007; Yiin et al., 2018; Kong et al., 2014; Mekhilef, 2011)

Oil palm biomass comes in a variety of forms, including empty fruit bunches, fruit fabrics, shells, tree trunks, and midribs, as well as Palm Oil Mill Effluent, or palm oil liquid waste. Up to $70 \%$ of current oil palm biomass is made up of palm tree fronds, while $10 \%$ is made up of hollow fruit bunches and 5\% is made up of oil palm trunks. Generally, up to 89 percent of total biomass generated is used as fuel, mulch, or fertilizer. Additionally, biomass may be turned into bio coal to be used in place of coal. Utilizing bio pellets or bio coal to fuel power plants is more environmentally sustainable than using fossil fuels and it will help offset greenhouse gas pollution.

Additionally, biomass-fueled power plants may be combined with palm oil processing plants to ensure that the electricity is still green. Simultaneously, its presence benefits the group significantly. The advantages are very substantial in terms of biomass energy supply. POME may be converted into biogas for domestic and industrial use. This pond scheme is easy and cheap, but it needs a vast amount of land and the methane trap is inefficient, resulting in greenhouse gas pollution from the lagoon. By trapping methane gas and transforming biogas to electricity, oil palm liquid waste may be used to generate energy that contributes to 
greenhouse gas reduction. Utilization of biogas is a form of renewable energy and is a component of the Government's policy to expand energy access for the community through the use of New Energy and Renewable Energy (EBT), especially bioenergy.

The philosophy of green energy that is focused on community engagement and benefits

\section{Technological Studies}

Renewable energy management needs infrastructure, and therefore should be considered a technical expenditure, since renewable energy processing over a long period of time would still be developed to generate energy from non-renewable natural resources. Future technological advancements will continue to render green energy management more youthful and effective.

\section{Simple to Build}

Renewable technology is simple to produce and has been utilized by a large number of people. A solar power plant is one such example. Numerous homes now have additional solar panels, allowing the advantages of clean energy from the sun to further reduce reliance on fossil fuels (Ayres \& Ayres, 2009; Shahsavari \& Akbari, 2018; Hosseini \& Wahid, 2020; Chu \& Meisen, 2011). Additionally, the cost of life would be reduced when the utilization is aided by the installation of solar cells.

\section{Waste Reduction}

Until now, the majority of waste has been produced from processed household waste and is often not handled properly, resulting in hygiene and health issues. Renewable energy production may aid in waste reduction; for example, biomass and biofuel are derived from the organic processes of plants and microorganisms. All of these energy sources have the potential to mitigate household waste.

\section{Opportunities for Jobs}

Renewable energy management would need more human capital to handle it. For instance, establishing a hydroelectric power plant in an environment that profits from the benefits of water energy would involve labor to construct and operate the plant, thus creating employment in the surrounding area.

\section{Biomass from Palm Oil Waste and Community Benefits}

The following rules govern the management and use of palm oil mill waste: (1) Environmental protection and enhancement (2) Economic feasibility (3) Recognized by the society and in compliance with applicable statutes. On the basis of these values, the following are several technical solutions for reusing palm oil waste.

\section{Utilization of Liquid Waste as Liquid Fertilizer}

The palm oil mill generates liquid waste during the explanation and hydrocyclone processes at a pace of approximately 0.65 tonnes / ton FFB. Due to the fact that this liquid waste contains between 20,000 and 30,000 parts per million BOD and a pH of 4-5, it must be treated to satisfy the consistency level specifications. This liquid waste contains organic matter that is very nutrient dense for plants, and therefore can be used as fertilizer for plants with a pH of 6-9 and a BOD concentration of 5,000 ppm.

To meet the criteria for land submission, liquid waste from the palm oil mill is treated biologically in the following steps: (1) Cooling tub, a tank used to cool liquid waste to a temperature that bacteria can tolerate. (2) Anaerobic bath, a pond in which microbes reduce 
liquid waste organic matter in the absence of oxygen. (3) Contact tank, a pond used to collect and test liquid waste prior to its distribution to the Land Application as liquid fertilizer.

How to repurpose land for oil palm plantations is a very amusing hypothetical topic. The general population has a propensity to assume that the transfer of natural capital in open areas to oil palm plantations is an established practice. It's straightforward; if we want to do it, we begin by identifying the appropriate location, then address technical issues, and so on, until we finally establish the oil palm plantation of our dreams. Although the definition may be condensed in this manner, the reality on the ground is frequently very different.

By examining the shape and management of oil palm plantations in Indonesia today, and taking into account that the majority of its procurement is motivated solely by economic benefit, it is possible to infer that the form of permit required for the conversion of land to oil palm plantations is a Plantation Business Permit for Management. Permits for oil palm plantations are needed by law. The first article establishes the license's legitimacy, while the second article governs the regulatory conditions for its acquisition.

\section{Participation of the Community in the Treatment of Oil Palm Waste}

The field observations of numerous oil palm commodity plantation businesses are very disparate. The author selects two cases from a sea of data. The local government appears to have missed up to 107 trillion dollars a year in possible revenue owing to unpermitted oil palm plantations. Following a surveillance procedure conducted by the parties involved, it was discovered that 1.4 million hectares of forest had been turned by local elements into illicit oil palm plantations.

The manner in which certain findings are presented directly violates the terms of the preceding regulations. To summarize, and returning to the previous clarification about ISPO, this illegal oil palm plantation breaches the central tenet of the law, namely the legality of the plantation company. The author believes that establishing the validity of oil palm plantations is a legal requirement, and that failing to do so violates relevant law. This is also stressed in Article 105 of the Plantation Law, which outlines the penalties applicable to anyone who engage in illicit oil palm plantation procurement:

Illegal oil palm plantations are a mistake, so what are the negative consequences implied by the title? It is possible to claim that these illicit plantations resulted in material and immaterial damages. The individuals concerned aim to establish a company based on illicit plantations for economic benefit and have previously evaded current regulations. The government and authorities have suffered a setback in this case because certain components are not abiding by or adhering to the existing regulations. The state has forfeited its right to profit from the presence of natural resources within its borders.

Not just that, but local people have felt the detrimental impact of these components' sports. By not adhering to established protocols, the purchase of illicit oil palm plantations has obliterated community gains. The author stresses that the term "loss of utilization" in this situation refers to the absence of income from the community's natural resources. Oil palm plantations that, if legitimate, should be able to sustain the lives of local residents as mentioned on the plantations, would become obstructed or even vanish entirely.

Not to mention that if illicit oil palm plantations are not adequately handled, they will leave toxic residues in and around communities. Why is this the case? Since it is possible that illegal oil palm plantation lands lack the allocation and planning of an Environmental Protection and 
Management Plan with the objective of preventing environmental harm, as defined in the environmental regulation. The author believes that these illegitimate oil palm plantation officers will behave arbitrarily, and even if environmental issues occur in the future as a result of inadequate plantation maintenance, they will absolve themselves of responsibility by simply leaving since the plantations they control are not legitimate, and the legal status of the plantation is irrelevant. The plantation remains in doubt.

Then there's the question of legitimate oil palm plantations. To begin, we must conclude that the primary focus should be on the oil palm plantation's management process. The authors would explain the negative consequences of different plantation managerization practices from two perspectives: the atmosphere and the culture. The detrimental effects on all of them is critical for us to understand because it can expose further raging issues that cannot be overcome easily and have a lasting effect.

The rapid growth of oil palm plantations, as shown by the previous Director General of Plantation, represents additional factors. Although it is possible that Indonesia profits economically most, how much green space is sacrificed? According to a geographical survey performed by Forest Watch Indonesia, the concession area of oil palm plantations in Indonesia was approximately 19 million hectares before the middle of 2017, with a natural forest cover of 2.3 million hectares within the oil palm plantation concession. Then, based on the same statistics, Indonesia witnessed deforestation of up to 2.81 million hectares, or approximately 49 percent, between 2013 and 2017, as a result of land use and use licenses issued by the government, with oil palm plantations accounting for the third largest contributor to deforestation at 586,531 hectares.

The author believes that the phenomenon of deforestation itself violates the following ISPO values, namely those pertaining to plantation management and environmental management and monitoring. The green area, which has been the bedrock of the nation and the country, must suffer a setback as a result of "wild" action directed towards it, regardless of how it occurs for the purpose of environmental growth and is founded on only rule. Consider the impact on the biodiversity habitat on the property used by the oil palm plantation. Additionally, consider the balanced estimate of the benefit and expense associated with the purchase of the land use transition and its continued life.

Additionally, the pattern of deforestation associated with oil palm plantations seems to deviate from the context of the Spatial Planning Law's provisions. The spatial planning theory embodied in this legislation seeks to establish a secure, convenient, efficient, and sustainable national territory space. In the basis of these goals, urban design is intended to strike a balance between the utilization of natural capital and the usage of land, while still avoiding unintended consequences of spatial use. If it is what urban design entails, so deforestation caused by oil palm plantations is not. Rather than providing a safe, convenient, and productive regional space, deforestation has become a venue for human action, destroying natural ecosystems that should be conserved in concert, and ultimately resulting in some truly horrific natural disasters.

This is not the end of the story; there are additional negative consequences of the oil palm plantation management mechanism's error. Most of these is the skyrocketing levels of carbon dioxide gas $(\mathrm{CO} 2)$. For every hectare of woodland transferred to oil palm cultivation, 174 tonnes of carbon are removed, the majority of which naturally enters the atmosphere. Indeed, evidence indicates that recent oil palm plantations emit more carbon dioxide than older plants. This assumes that the rise in the area of oil palm plantations from year to year is proportional to the increase in carbon dioxide levels in the environment caused by the opening of oil palm 
plantations, or it may be more, given the existence of illicit oil palm plantations whose legitimacy is unknown. Additionally, there are environmental consequences such as water and soil runoff, crop degradation, and climate change.

If the detrimental influence of its management has reached that level on the climate, what effect would it have on the population (legal oil palm plantations managed poorly)? There are a few tacit comments about this subject in the author's clarification above. According to the scientist, the detrimental effects of oil palm plantations on the surrounding area has had a significant impact on the lives of the population. In other terms, if there is even a single negative impact on the world, the negative effect will eventually spread to the population. This will be shown in the following explanation.

Regardless of legitimacy, the oil palm plantation's presence is very detrimental. For example, the influence of oil palm plantations on natural capital in green land has decreased or even vanished. Indeed, the biological organisms that inhabit it are the primary source of life for the population, especially the indigenous people who live in close proximity to the soil. If more oil palm plantations are grown, how can people who rely on the missing green nature survive? This is precisely what happened to the Malind tribe in the Papua area. Unlike in the past, the Malind people say that it is becoming increasingly difficult to obtain foodstuffs such as sago palms, pork, and cassowary, as well as vegetables and fruits, in their region due to the expansion of deforestation and oil palm agribusiness.

Additionally, there are detrimental consequences such as air degradation, which directly affects the local population. Managers commonly use fertilizers and pesticides containing some chemicals during the development of oil palm plants as a means of intensification to ensure that the oil palm plant grows optimally and produces high-quality crude oil. However, in certain instances, the process for controlling oil palm plantations that use these fertilizers and pesticides has been flawed. Due to this mistake, used fertilizers and chemicals are not properly disposed of - they are not truly disposed of according to established protocols, since the majority of them settle into the field or are swept away by rainwater to the nearby shore, disrupting stability. Additionally, the habitat degrades the climate of the surrounding inhabitants, since there is no productive ground for planting plants or a clear river for recreation briefly (or even permanently).

Examining the seven ISPO concepts listed previously reveals another apparent inconsistency, this time centered on three points: plantation management, conservation of primary natural forests and peatlands, and environmental management and monitoring. Additionally, the authors contend that the pattern of environmental degradation associated with the abovementioned plantation operation interventions violates a variety of provisions. For instance, land clearing and processing are governed by Article 23 of the Plantation Law, which reads as follows:

So, what should we achieve together as a result of all of this? The author has many claims to create. To begin, it requires a firm commitment from the oil palm plantation's management. This is important because any decision made while handling oil palm plantations, whether positive or negative in outcome, is made internally at the oil palm plantation. There must be assurance that the persons responsible for administration genuinely carry out plantation operations in compliance with relevant laws and regulations. As a result, it may significantly reduce or entirely remove multiple mistakes that result in negative consequences when a management mechanism is applied. 
Additionally, the government and relevant authorities must take a strong stance against any detrimental consequences. If we re-read the author's explanation above, we see that several breaches of existing legislation have occurred. This indicates that the rules are not being implemented properly. It is pointless to have a guiding rule but no legal intervention in the region. As a result, the writers emphasize the importance of the government and associated officials taking a strict stand on oil palm plantation management, one of which can be accomplished by the usage of suitable and reliable legal instruments.

Apart from that, the cases between these landowners demonstrate that the detrimental impacts of oil palm plantation management in Indonesia span a broad range, most notably in terms of the climate and culture. The author believes that marches or movements organized by locals directly impacted by oil palm plantation operations are legal. The government can react to these types of agitation or movement with a cautious and pro-public mindset, ensuring that the action's demands are followed up and investigated further to provide a remedy that is beneficial and equitable to both parties.

Finally, collaboration between the government in power, the management of oil palm plantations, and the citizens concerned is critical to ensuring that there are no further mistakes in the oil palm plantation management process that result in unintended consequences. Oil palm plantations and a sick ecosystem are inextricably linked. As the author said at the outset, the presence of oil palm plantations as a competent natural resource that has a significant effect on the Indonesian economy is analogous to the two sides of a knife; on the one hand, they are lucrative, but on the other, they provide us with challenges. The three parties' interconnected synergy — the government, managers, and citizens - would provide an agency that combines these two forces, ensuring that oil palm commodities have the capacity to sustain life in a way that benefits the Indonesian population as a whole.

\section{Conclusion}

Managers commonly use fertilizers and pesticides containing some chemicals during the development of oil palm plants as a means of intensification to ensure that the oil palm plant grows optimally and produces high-quality crude oil. Given that the procurement's primary purpose is economic benefit, it is reasonable to infer that the form of permit required for the conversion of land to oil palm plantations is a Plantation Business Permit for Management. Oil palm plantations need a permit. The justification for the license's creation, while the subsequent articles regulate the administrative conditions for its acquisition.

\section{References}

Ayres, R. U., \& Ayres, E. H. (2009). Crossing the energy divide: moving from fossil fuel dependence to a clean-energy future. Pearson Prentice Hall.

Chu, Y., \& Meisen, P. (2011). Review and comparison of different solar energy technologies. Global Energy Network Institute (GENI), San Diego, CA.

Hosseini, S. E., \& Wahid, M. A. (2020). Hydrogen from solar energy, a clean energy carrier from a sustainable source of energy. International Journal of Energy Research, 44(6), 4110-4131.

Kelly-Yong, T. L., Lee, K. T., Mohamed, A. R., \& Bhatia, S. (2007). Potential of hydrogen from oil palm biomass as a source of renewable energy worldwide. Energy Policy, 35(11), 5692-5701. 
Kong, S. H., Loh, S. K., Bachmann, R. T., Rahim, S. A., \& Salimon, J. (2014). Biochar from oil palm biomass: A review of its potential and challenges. Renewable and sustainable energy reviews, 39, 729-739.

Mekhilef, S., Siga, S., \& Saidur, R. (2011). A review on palm oil biodiesel as a source of renewable fuel. Renewable and Sustainable Energy Reviews, 15(4), 1937-1949.

Shahsavari, A., \& Akbari, M. (2018). Potential of solar energy in developing countries for reducing energy-related emissions. Renewable and Sustainable Energy Reviews, 90, 275-291.

Yiin, C. L., Quitain, A. T., Yusup, S., Uemura, Y., Sasaki, M., \& Kida, T. (2018). Sustainable green pretreatment approach to biomass-to-energy conversion using natural hydrolow-transition-temperature mixtures. Bioresource technology, 261, 361-369. 